\title{
Design e Fotografia: Relação e Aproximações
}

\section{Design and Photography: Relations and approximations}

\author{
SHIMODA, Flávio; Mestre; Universidade Anhembi Morumbi \\ shimoda.f@gmail.com \\ OLIVEIRA, Mirtes Cristina Marins de; Doutora; Universidade Anhembi Morumbi \\ mirtescmoliveira@gmail.com
}

\begin{abstract}
Resumo
Este artigo reúne um conjunto de apontamentos e reflexões, resultado parcial do desenvolvimento da pesquisa de uma tese de doutorado realizada junto ao Programa de PósGraduação em Design da Universidade Anhembi Morumbi, sobre as relações históricas e as aproximações teóricas possíveis de estabelecer entre design e fotografia. Tomados como vocábulos cunhados no processo da revolução industrial dos séculos XVIII e XIX, para significar aspectos de uma nova realidade emergente, os termos revelam dimensões ideológicas engajadas ao processo de subsunção do trabalho ao capital, e consequentemente ao processo de dominação da paisagem e da cultura social e sobre o corpo e o pensamento dos sujeitos nas sociedades contemporâneas. A luz do pensamento de Vilém Flusser os termos design e fotografia são questionados em suas dimensões semânticas como processos fraudulentos contra a natureza e que anunciam um estágio de mudança na postura existencial do sujeito em sociedade.
\end{abstract}

Palavras Chave: design; fotografia; cultura e sociedade.

\begin{abstract}
This article brings together a set of notes and reflections, a partial result of the research development of a doctoral thesis held at the Anhembi Morumbi University Graduate Program in Design on historical relations and the possible theoretical approaches to establish between design and photography. Taken as words coined in the process of the industrial revolution of the eighteenth and nineteenth centuries, to signify aspects of a new emergent reality, the terms reveal ideological dimensions engaged in the process of subsumption of labor to capital, and consequently to the process of domination of landscape and culture social and on the body and the thinking of the subjects in contemporary societies. The light of Vilém Flusser's thinking the terms design and photography are questioned in their semantic dimensions as fraudulent processes against nature and that announce a stage of change in the existential posture of the subject in society.
\end{abstract}

Keywords: design; photography; culture and society. 


\section{Introdução}

Design e fotografia enquanto termos são vocábulos totalmente assimilados pelo fluxo do discurso social contemporâneo. Pela familiaridade decorrente do uso cotidiano e exaustivo destes termos, alimenta-se sobre eles uma noção de senso comum, de um conhecimento generalista impregnados de preconceitos oriundos da publicidade e do jornalismo, que reduz os significados dos termos: design a um adjetivo que agrega valor comercial a um determinado produto industrial e fotografia a um substantivo que define uma forma específica de registro documental da realidade. Neste contexto arbitrário do entendimento do senso comum, os termos são deliberadamente simplificados para omitir uma dimensão complexa que só pode ser revelada por uma crítica histórica e social.

A tarefa de construir uma crítica histórica e social do design e da fotografia é uma estratégia metodológica para investigar que relações podemos estabelecer entre estes dois termos e de que natureza seria estas relações. Para Webb (2015), em seu livro "O design da fotografia", o design é definido como um campo específico, especializado em técnicas de comunicação visual, que empresta estes conhecimentos para o fotógrafo pensar a composição do enquadramento do registro de suas imagens. Sendo o design fotográfico um processo de domínio dos elementos: forma, iluminação e cor; repetição, ritmo e contraste; profundidade e escala; movimento e fluxo; ênfase e emoção. Como um manual para fotógrafos iniciantes, Webb nos oferece um exemplo da abordagem que propomos superar, pois ele parte da premissa do design como uma disciplina de finalidades práticas baseada na noção de projeto de comunicação visual, que se vincula a fotografia apenas como conhecimento acessório. Acreditamos que uma crítica histórica e social possa nos auxiliar a entender simultaneamente como cada um dos termos ganhou os seus significados distintos no discurso contemporâneo, a partir de uma origem em comum no berço da Revolução Industrial.

A perspectiva de uma crítica histórica e social, além de buscar uma melhor compreensão dos processos colocados em curso no passado, nos serve para entender a atualidade, que nos impõe de forma centralizada um processo de digitalização social em massa, baseada em redes de conexão de computadores, proporcionada pelo capital técnico e tecnológico base da infraestrutura eletroeletrônica de processamento de dados, criada e instalada a partir do século $X X$. Neste contexto atual de dominação do capital tecnológico, os termos design e fotografia, se desdobram como conceitos teóricos engajados a processos de produção social de subjetividade. Onde a imagem fotografia torna-se uma peça fundamental na dinâmica projetiva do controle social. Como dado digital, a fotografia passa a ser calculada, tornando-se matéria prima a ser coletada em redes de compartilhamento sociais. E o design avança como uma consciência projetiva que além de projetar a forma dos produtos materiais e da paisagem, passa a projetar as formas dos produtos imateriais e do comportamento social.

Neste contexto do desenvolvimento da humanidade, segundo o pensador Vilém Flusser, se situa o cenário e os agentes, do que para ele é a maior revolução cultural do processo civilizatório, onde se anuncia a mudança de atitude existencial do sujeito, que passa abandonar a noção de indivíduo para assumir a noção de projeto no interior de uma sociedade programada, onde design e fotografia assumem e revelam suas dimensões ideológicas, como processos ativos de 
transformações da natureza e do corpo humano, criando uma realidade artificial aparentemente simples e naturalizada, mas fundada em um conjunto complexo de códigos calculados.

\section{Breve História Social do Design}

A proposta historiográfica de uma história social do design que nos interessa aqui, não se vincula a uma narrativa das transformações dos estilos estéticos e funcionais dos produtos industriais ou das propostas pedagógicas das escolas de design ao longo do século XIX e XX, mas a uma abordagem que permita refletir de um ponto de vista distante essas realidades históricas descritas e nos aproximar dos processos sociais que formularam as demandas do emprego do termo design e posteriormente a sua conceituação como objeto teórico da reflexão contemporânea do século XXI.

A origem do termo design como palavra do vocabulário remonta ao século XVIII, que é reconhecido historicamente como um período de ruptura que marcou o início de profundas e constantes transformações em todas os níveis sociais: na esfera privada familiar, na esfera pública, nas relações de trabalho, nos discursos ideológicos e nas esferas do conhecimento. Trata-se do período de emergência de uma nova realidade cultural, baseada em novos arranjos econômicos e políticos, inter-relacionados ao processo de industrialização, ao fortalecimento dos Estados nacionais, ao enraizamento dos interesses das organizações multinacionais de capital e do surgimento dos movimentos sociais de massa. É nessa nova paisagem, desenvolvida, diferenciada e dinâmica que temos o lugar da experiência moderna (BERMAN, 1986). Experiência vertiginosa movida a transformação, que se alimenta do conhecimento científico convertido em tecnologias de produção ou de entretenimento social. Neste contexto de alta complexidade, os sujeitos tateiam "em estado de semicegeira, no encalço de um vocabulário adequado" (BERMAN, 1986, p. 25), que permita tornar inteligível e comunicável esta nova experiência existencial que se conforma cotidianamente, num perpétuo movimento de vir-a-ser, que conhecemos com "modernização" (BERMAN, 1986, p. 25). Esse período descrito como época de progresso das sociedades modernas, deve ser entendido como sinônimo das novas tensões provocadas pelo desenvolvimento do capital industrial. E é no interior dessa densa e complexa realidade emergente, que se impõe a necessidade específica de um novo vocabulário que signifique e que nos permita conhecer uma nova postura da ação humana frente ao trabalho de transformação do dado da natureza para o feito industrialmente. A palavra design, no contexto da língua inglesa do século XVIII, é forjada para dar significado a esta nova postura da ação humana.

No entanto, o advento de um termo não encerra o seu processo de significação, pelo contrario, ele marca o inicio formal deste processo. Neste sentido o termo design surge inicialmente como uma expressão genérica e imprecisa para designar uma realidade emergente, relacionada as novas formas de organização social do trabalho, imposta pelo processo de industrialização como conseqüência do processo de subsunção do trabalho ao capital. Essa nova realidade contrasta com a realidade medieval historicamente anterior, baseada no trabalho artesanal desvinculado do processo de geração de riqueza capitalista. Porém este vinculo, hoje revelado entre design e capitalismo, não era algo evidente e nem problematizado no século XIX. Nesse período inicial o significado do termo design se restringe ao aspecto da configuração da forma dos produtos industriais, cristalizado pela doutrina da "boa forma" (FORTY, 2007, p. 08). Design era tido essencialmente como uma prática de modelagem de formas belas, como um 
processo de racionalização com o objetivo de proteger o consumidor da corrupção moral pública, do desperdício de material e de trabalho e da degenerescência cultural do "mau design" (FORTY, 2007).

Este tipo de pensamento divulgado e reproduzido por anos, principalmente nas escolas de design no século $\mathrm{XX}$, como máxima incontestável na formação dos designers, contribuiu para a atrofia teórica da área, ocultando o design como um produto social de um estágio do capitalismo, empenhado na criação de riqueza industrial. O que condenou o design a fútil "condição de mero apêndice cultural", como uma atividade puramente artística (FORTY, 2007, p.12). Neste contexto, foi nulo qualquer esforço em compreender a cultura material e a história da mercadoria no contexto do capitalismo, bem como foi ignorado qualquer "influência do design em nossa forma de pensar" (FORTY, 2007, p.12). Simultaneamente o termo passa a se popularizar no discurso social através do jornalismo e da publicidade como um adjetivo simplificado para designar status comercial de um determinado produto industrial, alienando o significado social do termo e o isentando de uma dimensão ética com a sociedade.

A partir da segunda metade do século $X X$, o termo passa a ser objeto de críticas especulativas e a ser sistematizado como um conhecimento teórico, que questiona os limites da significação do termo aplicados desde o século XVIII. Design, como objeto teórico, supera a sua definição de status, para ser pensado como uma conseqüência histórica (CARDOSO, 2004), como uma conseqüência necessária para construir manuais e interfaces de uso de uma realidade moldada pela tecnologia, cada vez mais complexa e abstrata. Passa-se também a reconhece o capitalismo como o sistema que define o design como um meio de articulação das tensões nas relações de valor de uso e valor de troca dos produtos. O que faz da tarefa do design, "de um lado projetiva entre tecnologia e materiais", e de outro, "cultural, na medida em que desenha informações e idéias" (FERRARA, 1993, p. 192). Ou seja, o 'design' deve dar conta da forma do produto enquanto coisa a ser projetada, simultaneamente ao processo de dar significado à coisa enquanto produto. Nesse sentido o design se revela como uma conseqüência intrínseca do capitalismo, pois é ele o responsável pelo projeto do produto, pela idéia que terão do produto e pela imagem de consumo do produto, na complexa rede da organização do trabalho.

O termo design, além dos vínculos já descritos passa também a se definir como uma disciplina do conhecimento, tornando-se um campo de formação universitário voltado a graduação de profissionais especializados. Por conta disso, amplia-se a discussão da definição disciplinar do design, como observado por Rita Maria de Souza Couto (1997), a tentativa de conceituar o 'design' é uma constante presente em quase todos os trabalhos de estudo que abordam algum aspecto do design. Como Löbach (2001) e Niemeyer (1997), Couto vai justificar que essa recorrência em diversos trabalhos advém do fato de que cada autor tem a necessidade de explicitar o seu entendimento sobre o que seja design. Seguindo a referência de Gomes (1993), Couto observa a riqueza contida na palavra, e nota que o termo design em inglês, entendido como verbo ou como substantivo, possui uma denotação próxima aos termos portugueses "desenhar" e "desenho", e denota também uma área do conhecimento humano que se "responsabiliza por arranjar, organizar, classificar, planejar, projetar e, principalmente, desenhar artefatos, mensagens, ambientes ou espaços para a produção industrial ou artesanal" (COUTO, 1997).

Numa tentativa de síntese, reconhecendo que o design está diretamente vinculado a um 
estágio da história do capitalismo e associado ao processo de criação e valorização da riqueza industrial, Forty (2007) extrai do senso comum duas definições básicas de design: 10.) refere-se à aparência das coisas, envolvendo as noções de beleza; 2o.) refere-se ao processo de formulação de instruções, projeto, para a produção de bens industriais. Sem desmerecer essas definições, ele posiciona a qualidade especial do termo design na conjunção simultânea de ambos os sentidos que expressa: "a aparência da coisas é, no sentido mais amplo, uma consequência das condições de sua produção" (FORTY, 2007, p.12), ou seja, "design coloca as ideias e crenças diante das realidades materiais da produção" (FORTY, 2007, p.14), que nos permita dar "formas tangíveis e permanentes sobre quem somos e como devemos nos comportar" (FORTY, 2007, p.12). Revelando sua capacidade de moldar mitos numa forma sólida e duradoura de tal modo que parece ser a própria realidade (FORTY, 2007, p.15).

Ao analisar o processo social do desenvolvimento da técnica no final do século $X X$, centrado na miniaturização dos motores, dos emissores-receptores e de outros microprocessadores, Virilio (1996) coloca estes processos no cerne da questão do que ele chama de design pós-industrial. Estabelecendo em sua argumentação uma distinção entre design industrial, voltado a formas dos objetos, e design pós-industrial (meta-design), voltado a modelagem dos costumes e dos comportamentos sociais.

Desde a noite dos tempos, o desenvolvimento da técnica se dá em direção ao horizonte terrestre e à superfície dos continentes, com a invenção dos sistemas hidráulicos, dos canais e das pontes e aterros: megamáquinas das quais as empresas ferroviárias e rodoviárias deveriam ser a realização plena graças ao equipamento das cidades, com as linhas elétricas ou o cabeamento completando o que a revolução do deslocamento físico já havia conseguido, e nos preparamos agora para equipar a espessura do que vive com micromáquinas suscetíveis de estimular eficazmente nossas faculdades, o inválido equipado para superar sua deficiência transformando-se subitamente em modelo para o válido superequipado com próteses de todos os tipos (VIRILIO, 1996, p. 92).

Como conclusão deste processo, Virilio observa que o meta-design não se preocupa mais em desenvolver uma forma de estrutura ou de infraestrutura dos objetos industriais, mas passa a operar no âmbito da neurociência, sobre o sujeito vivo, como uma espécie de "ergonomia cognitiva, último tipo de conexão neuroléptica que se poderia chamar de INFRAESTRUTURA do comportamento" (VIRILIO, 1996, p. 95)

Tanto Virilio, com Forty, por caminhos analíticos diferentes apontam com o desenvolvimento conceitual do termo design, para a percepção de que este para além do seu propósito de configuração de produtos industriais, visa também projetar a forma do sujeito social, tanto na dimensão do seu corpo como na dimensão do seu pensamento.

\section{Breve História Social da Fotografia}

Parafraseando o título do celebre texto de Walter Benjamim (1996) o que propomos aqui, não se trata de um inventário dos fotógrafos ou de uma análise centrada na estilística ou nos temas históricos das imagens fotográficas, o que nos interessa é a fotografia enquanto técnica fruto de um processo histórico atrelado ao domínio capitalista sobre a realidade social.

A imagem conhecida como "Vista da janela em Le Gras", produzida entre 1826 e 1827 na região de Borgonha na França por Joseph Nicéphore Niépce (1765-1833), por um processo que ele 
nomeou de heliografia, é conhecida historicamente como a primeira fotografia, ou mais especificamente, a primeira imagem gravada pela ação direta da luz feita em uma câmera que conhecemos e que sobreviveu ao tempo. O processo consistia na gravação da imagem ótica obtida por uma câmara escura equipada com lentes convergentes. Niépce utilizou como suporte de gravação uma placa de peltre, que é uma liga metálica composta por estanho, cobre e chumbo, revestida com betume branco da Judéia, que tem como uma das suas propriedades ser fotossensível, endurecendo quando atingido pela luz. Utilizando uma câmara desenhada e fabricada por Charles Louis Chevalier (1804-1859), Niépce posicionou sua placa fotossensível no interior da câmara de forma que sobre ela se projetasse a imagem luminosa obtida pela lente. Segundo os relatos históricos, Niépce expôs a placa fotossensível a luz da imagem ótica por oito horas, com a câmara apontada para uma janela do sótão da sua casa de campo, em Chalon-surSaône, mostrando-nos a paisagem dos telhados de parte de sua propriedade. Após exposta, a placa revestida por betume branco da Judéia foi submetida a um banho em óleo de alfazema, que diluiu as áreas do betume que não foram atingidas pela luz, obtendo como resultado final uma imagem positiva em baixo relevo.

Figura 1 - "Vista da janela em Le Grãs"

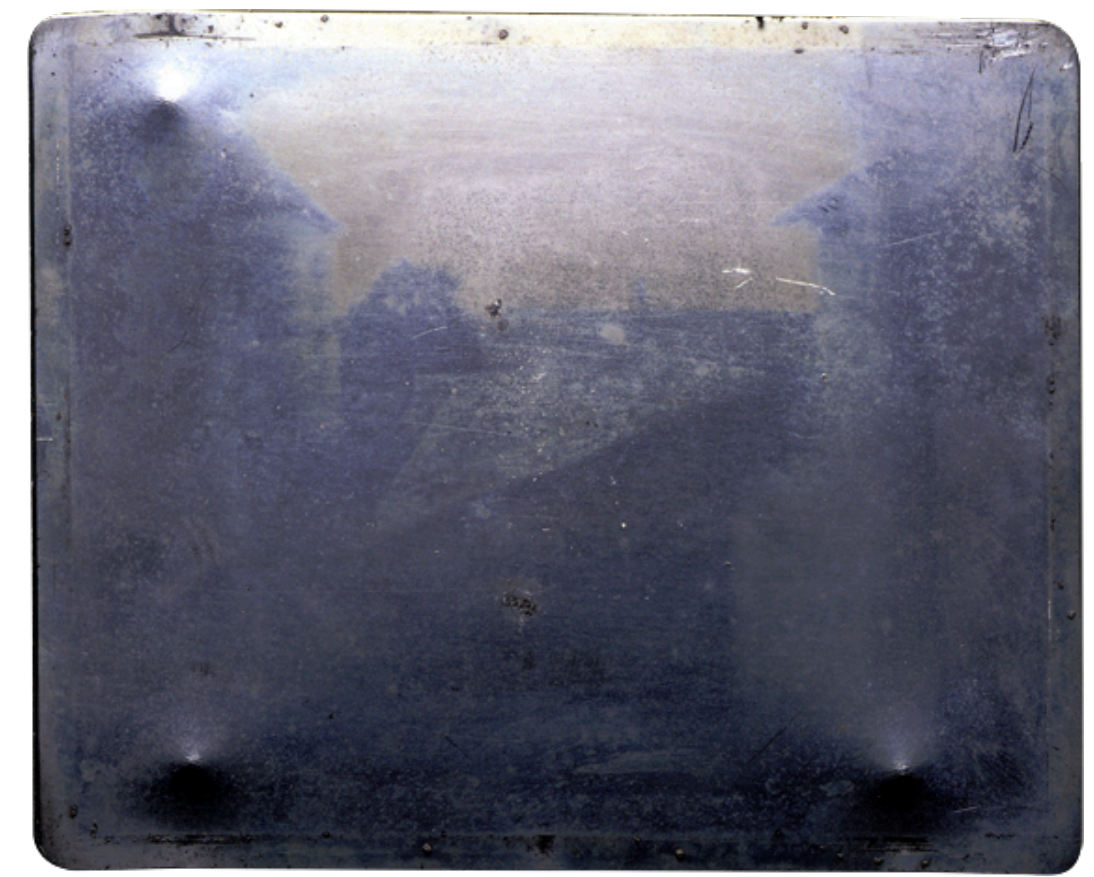

Fonte: http://www.hrc.utexas.edu/exhibitions/permanent/firstphotograph/ (2018)

Este artefato hoje preservado no Harry Ranson Center na Universidade do Texas em Austin, é um importante marco histórico no desenvolvimento da fotografia como produto social. Pois ele materializa um projeto iniciado pelo menos desde o Renascimento.

A perspectiva central e unilocular inventada no Renascimento introduziu nos sistemas pictóricos ocidentais a estratégia de um efeito de "realidade" e fez com que os seus artífices mobilizassem todos os recursos disponíveis para produzir um código de representação que se aproximasse cada vez mais do "real" visível, que fosse o seu análogo 
mais perfeito e exato (MACHADO, 2015, p. 31).

Neste sentido a fotografia não surge como uma descoberta ou invenção, mas como um arranjo do desenvolvimento técnico que soluciona a necessidade de automatizar um processo previamente projetado, para simular a aparência de realidade, fundada na "certeza tautológica de que uma imagem constituída segundo a sua concepção de objetividade é verdadeiramente objetiva" (MACHADO, 2015, p. 25). Ou seja, a fotografia como produto técnico que registra de forma análoga o "reflexo bruto da "realidade" só se pode justificar com postura estratégica, isto é, ideológica” (MACHADO, 2015, p. 41).

A fotografia como expressão ideológica vinculadas ao projeto decorrente da Revolução Industrial tem um papel fundamental "enquanto possibilidade inovadora de informação e conhecimento, instrumento de apoio à pesquisa nos diferentes campos da ciência e também como forma de expressão artística" (KOSSOY, 2011, p. 25). Enfatizando esta consequência da fotografia, Walter Benjamin cita em sua "Pequena História da Fotografia", a defesa do físico Arago sobre descoberta de Daguerre, "Quando os inventores de um novo instrumento o aplicam à observação da natureza, o que eles esperavam da descoberta é sempre uma pequena fração das descobertas sucessivas, em cuja origem está o instrumento" (BENJAMIN, 1996, p. 93).

Observando a fotografia como um produto industrializado de uma cultura de massa Benjamin (1996) se questiona "se a invenção da fotografia não havia alterado a própria natureza da arte". Notando que a reflexão inicial sobre a fotografia ocorria numa relação polarizada entre fotografia e pintura, sobre o valor artístico da imagem fotográfica, e a partir de fundamentos marxistas, ele propõe um prognostico com a teses sobre as "tendências evolutivas da arte, nas atuais condições produtivas" (BENJAMIN, 1996, p. 166), onde a fotografia tem uma função importante, pois "pela primeira vez no processo de reprodução da imagem, a mão foi liberada da responsabilidade artísticas", o que acarreta materialmente em uma aceleração no processo social de produção dessas imagens e em uma nova relação com a esfera de autenticidade, superando tradições enraizadas sobre a significação dos objetos.

Com o desenrolar do século XX, a fotografia passa a ser objeto de reflexão do campo da Semiótica, e Arlindo Machado (2015) nos apresenta nos termos da teoria do signos de Charles S. Peirce, um mapa bibliográfico de um conjunto de abordagens semióticas sobre a fotografia, que a enfatiza "ora em sua iconecidade (Cohen 1989: 458; Sonesson 1998), ou seja, em sua analogia com o referente ou objeto e em suas qualidades plásticas particulares, ora em sua indexilidade (Dubois 1983: 60-107; Schaeffer 1987: 46-104), isto é, em sua conexão dinâmica com o objeto (é o referente que causa a fotografia), ora em uma e outra ênfases simultaneamente (Santaela e Nöth 1998: 107-39; Sonesson 1993: 153-4)" (MACHADO, 2001, p. 122). Dentro deste campo, Phillippe Dubois (2014) em "O Ato Fotográfico", problematiza a relação da imagem fotográfica com a realidade. Em uma perspectiva histórica ele classifica três momentos de abordagem crítica e teórica sobre a imagem fotográfica: "a fotografia como espelho do real (o discurso da mimese)"; "a fotografia como transformação do real (o discurso do código e da desconstrução)"; "a fotografia como traço de um real (o discurso do índice e da referência)" (DUBOIS, 2014, pp. 26). Ele fundamenta em Ch. S. Peirce e em Roland Barthes argumentos para defender a tese da sua terceira abordagem histórica, a fotografia como traço de um real, onde se discute a ontologia da imagem fotográfica, sob ótica da "noção de índice (por oposição a ícone e símbolo)" (DUBOIS, 
2014, pp. 27), "a imagem indiciária é dotada de um valor todo singular ou particular, pois determinado unicamente por seu referente e só por este: traço de um real” (DUBOIS, 2014, pp. 45).

A fotografia além de suas propriedades semióticas inerentes, predominantemente dada pela imagem que ela porta, simultaneamente detém a condição de objeto, a condição de imagem, tem uma natureza fragmentada, é um registro documental, um registro expressivo, tem uma autonomia e uma realidade própria, e é permeada por ambiguidades (KOSSOY, 2001). A enumeração dessa complexidade da fotografia, contrasta com a simplicidade tecnológica do ato fotográfico nas sociedades contemporâneas.

Como produto histórico atrelado a um estágio do capitalismo, a fotografia não foi descoberta ou inventada, como narra o discurso oficial da história, ela é um resultado de um projeto que visa atender expectativas específicas. As expectativas por trás do projeto da fotografia, são os interesses da burguesia como classe em ascensão (COSTA, 2004), em obter formas eficientes de controle da paisagem e da percepção.

O princípio da fotografia é uma forma de comportamento ótico da luz, que hoje passou a ser calculada dando origem ao que conhecemos como fotografia digital. Neste novo estágio a fotografia é aplicada em sua potência máxima como instrumento de controle sobre a paisagem e a consciência, dotada de um nível maquiavélico de astúcia, fralda a natureza e a percepção, e com um funcionamento complexo de modo operativo simples, mobiliza o sujeito em um engajamento automático ao projeto fotográfico da cultura contemporânea, que visa em último instância alimentar uma rede de interconexões.

\section{Aproximações Teóricas entre Design e Fotografia}

A definição do conceito de indústria cultural, proposto por Adorno e Horkheimer, talvez hoje possa ser aplicada para indústria como um todo. A lógica ideológica por de trás de toda indústria é a dominação econômica, para a reprodução do lucro, sendo em função deste que se opera o desenvolvimento da técnica, que nos trouxe a padronização e a produção em série, operando um controle de forma centralizada que recalca qualquer forma de consciência contrário (ADORNO, 1985, p. 114). Neste contexto histórico o mundo é forçado a se organizar industrialmente, que passa a controlar não só a transformação da paisagem, mas a subjetividade do sujeito enquanto massa. O logro, torna-se elemento central nesta lógica de dominação, pois tudo é colocado no devir. "A promissória sobre o prazer, emitida pelo enredo e pela encenação, é prorrogada indefinidamente: maldosamente, a promessa a que afinal se reduz o espetáculo significa que jamais chegaremos à coisa mesma" (ADORNO, 1985, p. 130-131).

O pensador Vilém Flusser propõe colocar a ideia do logro na base da cultura humana. Para ele o ser humano é um ser para morte, aprisionado em um corpo, sendo esta a sua condição na natureza. No entanto a consciência humana não suporto esta condição natural e projeta cultura, que é um projeto de lograr a natureza, pois na realidade abstrata da cultura, o homem encontra a ideia de sentido e pode sonhar com o horizonte da liberdade (FLUSSER, 2007). Ao definir o design, Flusser novamente invoca a ideia de lograr a natureza, com o exemplo da alavanca, no entanto ele acrescentou o elemento da malícia. $O$ que nos permite entender que o lograr a natureza pode ser uma postura de desespero e de alienação, ou uma postura consciente e maliciosa. Sendo design a 
segunda postura, a postura projetiva.

A idéia de lograr a natureza deriva da definição do homem, como um ser que nega a natureza. O helenista Eudoro de Souza é outro autor que também definir o homem como um ser que nega "o que gratuitamente Ihe deram e gratuitamente lhe dão" (SOUZA, 1984, p. 17), para construir o seu próprio mundo. Flusser nos diz que ao negar a natureza o homem se comunica, cria a língua que reveste o caos absurdo da natureza com significados e sentidos: cria realidades. Para ele realidade é fruto da língua, o que nos permite falar de realidades no plural, pois cada língua será uma realidade diferente.

Além dessa equivalência entre língua e realidade, ele nos propõe um modelo histórico fenomenológico sobre os estágios materiais da relação do homem com o mundo, que ocorre através do seguintes estágios: manipular, ver, escrever, mover e calcular. Cada estágio desses também representa níveis do grau de abstração do homem frente ao mundo. Indo do grau zero ao grau quatro. O estágio do cálculo, inaugurado, segundo ele, pela fotografia, é uma abstração de quarto grau. Neste estágio o homem é um ser totalmente alienado de sua natureza, vive numa totalidade artificial codificada, e é neste contexto que floresce a consciência operativa do design, primeiro como uma mediação por objetos e depois como uma mediação por pensamento. A distinção do design em dois níveis operativos também é enunciada por Paul Virilho (1996), como design no âmbito da configuração das formas dos objetos na era industrial, e como meta-design no âmbito da configurações dos costumes e comportamentos na era pós-industrial.

Em "Design como teologia", Vilém Flusser (2007) discutir a dicotomia Ocidente e Oriente e a divergência existencial dessas duas esferas culturais, ilustrada da seguinte forma: "No Ocidente é preciso morrer (esse é o preço dos pecados) e no Oriente é preciso sempre reencarnar (essa é a punição pelos delitos cometidos). Para o Ocidente, "salvação" significa a superação da morte; para o Oriente a superação das reencarnações. Cristo promete a vida eterna; Buda, a libertação da vida" (FLUSSER, 2007, p. 206). No entanto para ele, esse distanciamento começa a se encurtar, e para discutir essa aproximação, ele toma o "rádio portátil" que é um produto da ciência Ocidental, com um design Oriental.

O rádio portátil japonês certamente não impõe à ciência aplicada do Ocidente uma forma oriental, mas trata-se de uma síntese em que ambos se complementam mutuamente" (p.207).

Segundo ele o design no Ocidente, "revela um homem que interfere no mundo", e que no oriente o design é um "modo como os homens emergem do mundo para experimentá-lo" (FLUSSER, 2007, p. 209). Mas essa diferença começa a se diluir, e a causa da diluição dessas duas esferas é o código digital dos computadores, pois nele desemboca a ciência Ocidental, baseada no pensamento linear e na regra da escrita alfanumérica, e o pensamento Oriental baseado nos ideogramas. Neste novo código digital, Ocidente e Oriente se encontram e se compreendem, ao mesmo tempo que geram uma nova motivação oculta. Dessa fusão que reconectam os dois lados do abismo, pode surgir, "uma ciência e uma tecnologia inclassificável cujos produtos estão desenhados com espírito que não se enquadra nas antigas categorias" (FLUSSER, 2007, p. 213).

Neste ponto Flusser formular a seguinte hipótese: "Será que esse design não é expressão de um cristianismo judaico "elevado" ("aufgehobener"), de um budismo "elevado", para os quais ainda nos faltam palavras?" (FLUSSER, 2007, p. 213). Como pista para o desenvolvimento desta 
hipótese, Flusser sugere submeter "esse design a uma análise "teológica" para saber se a atitude diante da vida e da morte está se situando em um novo plano?" (FLUSSER, 2007, p. 213). Para responder esta questão, acreditamos ser necessário entender como Flusser define a atualidade em que esse design se circunscreve dentro do seu paradigma histórico e a fase em que nós nos localizamos. Ao formular o seu paradigma histórico, ele nos propõe um modelo que considera o homem diante de sua relação com o mundo. Ele parte da premissa que o homem é incapaz de estabelecer uma relação direta com o mundo, e diante dessa incapacidade, o homem cria a dimensão da cultura, como dimensão operativa do homem na sua relação com o mundo. Segundo ele a cultura se desenvolve em quatro estágios, que também indica graus de abstração e/ou afastamento do homem e do mundo. O estágio zero ocorre na pré-história quando o homem opera manualmente através de ferramentas que simulam uma extensão do seu corpo, ainda na pré-história o homem cria a imagem sobre superfície simulando o seu sentido de visão, que seria o primeiro estágio. O segundo estágio marcar o fim da pré-história início da história, quando o homem estabelece a escrita linear, simulando a linguagem oral. O terceiro estágio ocorre quando o homem cria a máquina que simula a força humana. O quarto e último estágio desse paradigma é

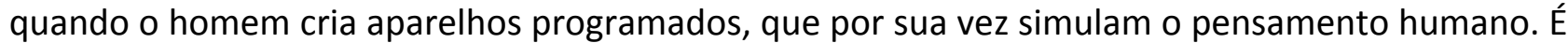
neste último estágio que devemos circunscrever o design que estamos tratando aqui. É o estágio em termos de dimensões, da "zerodimensão", onde nos relacionamos com o mundo por imagens sintéticas ao toque do dedo (FLUSSER, 2008). É neste contexto abstrato que devemos nos indagar sobre a mudança da postura existencial humana. No estágio em questão a noção de programa e projeto torna-se uma constante baseado em cálculos, tudo passa ser calculado e transformado em imagens sintéticas. A existência no mundo e o próprio mundo passa ser um programa projetado. $\mathrm{E}$ provavelmente é aí que se opera a mudança da atitude existencial, abandonamos a noção de determinismo, destino e causalidade para vivenciarmos a ideia de programa (FLUSSER, 2011).

Quando Flusser trata da palavra design, ele reconhece que ela ocupa um espaço significativo no discurso contemporâneo, perseguindo o seu significado semântico, ele chegar na relação do termo com o significados de "astúcia" e "fraude", que lhe permite definir o designer como "um conspiradores malicioso que se dedica a engendrar armadilhas" (FLUSSER, 2007, p.182). Aproximando design de outros termos, ele evidencia a forte inter-relação que a palavra guarda com as palavras máquina, técnica, ars e kunst ("a palavra "arte" em alemão, kunst, é um substantivo que deriva do verbo poder, können)" (FLUSSER, 2007, p. 183). E nos diz que esta interrelação foi ocultada pelo menos desde o renascimento, criando na cultura burguesa a distinção das ciências e das artes, como campos isolados. Na brecha desse abismo a palavra design funciona como uma ponte. Mas na verdade o que une esses termos é a condição semântica de engodo e malícia, e é esse o significado do "design que está na base de toda cultura: enganar a natureza por meio da técnica, substituir o natural pelo artificial e construir máquinas de onde surja um Deus que somos nós mesmos", ou seja, "com astúcia, nos transformamos de simples mamíferos condicionados pela natureza em artistas livres" (FLUSSER, 2007, p. 184).

Para ele: "O olhar do designer, seja divino, seja homem, é, sem dúvida aquele olhar do segundo olho da alma" (FLUSSER, 2007, p. 189), e seguindo uma tradição platônica, como ele mesmo reconhece, teoria é o modo de ver do segundo olho da alma, é quando percebemos "por meio dos fenômenos fugazes, formas eternas e imutáveis ("Ideia")" (FLUSSER, 2007, p. 189), agora indo para um lado diferente de Platão, ele não acredita que as "ideias" são descobertas, mas 
inventadas: "a geometria teórica (e a mecânica teórica) é um design ao qual submetemos os fenômenos para poder tê-lo sob controle" (FLUSSER, 2007, p. 190). Ou seja, design é uma consciência empenhada a criar armadilhas como meio de obter poder. Mas se as ideias ou formas eterna são invenções, porque o mundo não é como gostaríamos que fosse? Esta questão que ele considere inevitável e inquietante, fica sem resposta. Mas aponta para o fato das formas, independente de serem descobertas ou inventadas, são eternas, pois "não estão no espaço e no tempo" (FLUSSER, 2007, p. 191). E é fato que "todas as formas eternas" (FLUSSER, 2007, p. 191) poder ser formulada em equações e calculados por aparelhos produtores de imagens sintéticas.

Para Flusser a fotografia formulada tecnicamente no século XIX é o marco inicial do quarto estágio do desenvolvimento da cultura humana. Para ele a fotografia a base de sal de prata é o primeiro aparelho produtor de imagens sintéticas. A primeira práxis a articular a mudança de atitude existencial do sujeito contemporâneo. E observa três aspectos da fotografia enquanto aparelho, que se aprofundam no contexto mais amplo da revolução cultural, que são: (1) estrutura granular; (2) simula a cognição humana: (3) ciência confunde-se com arte.

(1) A fotografia a base de sal de prata é imagem granular, o que sempre gerou o problema da "definição" da imagem, em comparação entre a experiência visual do objeto e a imagem fotográfica. Flusser entende esta questão no sentido de se tratar inicialmente de uma distinção entre imagem e imaginado, mas que com a fotografia de alta resolução o universo das imagens fotográficas se tornariam indistinguível do universo dos objetos. Sendo projeto humano o universo das imagens e dos objetos, Flusser conclui que com o aparelho fotográfico "o homem se assume projeto de mundo" (FLUSSER, S/D).

(2) A fotografia "simula a percepção visual, e com isto inaugura a evolução que vai simular progressivamente processos mentais de mais em mais complexos (o calculo, a memória, a decisão, o raciocínio lógico, a composição musical, a criatividade poética, a elaboração de imagens)" (FLUSSER, S/D). Flusser observa que nesse novo contexto cultural, o ser humano deixaria de concentrar interesse na atividade mental, e passaria a programar tal atividade. A história da fotografia ilustra isto, no início acreditávamos que o fotógrafo manipulava a técnica fotográfica, hoje percebemos que a fotografia se faz automaticamente seguindo uma programação. Para Flusser isso revoluciona o conceito de "imaginação": "não mais a concebemos enquanto capacidade de fazes imagens (autômatos o fazem), mas enquanto capacidade de programar a execução de imagens. No fotografar (e nos gestos decorrentes disto), o homem deixa de ser sujeito, e passa a projeto" (FLUSSER, S/D).

(3) A fotografia como técnica é práxis informada de teoria, é consequência do discurso da ciência. No entanto o produto da fotografia é uma imagem, e para Flusser imagens são modelos de vivências, o que ele define como "Arte". Com a fotografia a técnica invade o território da arte: "modelar vivencias é impor significados, e isto é a função da arte: dar sentido a vida. Com a foto se inicia toda uma serie de gestos informados por teorias que visam conscientemente a imposição de significados sobre existência absurda em mundo absurdo. $O$ homem vai se assumindo projeto para significados" (FLUSSER, S/D).

O inovador na abordagem de Vilém Flusser sobre a fotografia, segundo Arlindo Machado (2001) é que ele fundamenta sua discussão na posição ontológica da fotografia a partir de uma densa teoria que se sustenta sobre o seu modelo fenomenológico da história da cultura. O que 
nos permite propor que os temas fotografia e design, estão interconectados no conjunto teórico de Flusser, pois ao tratar do design como uma consciência do projeto e a fotografia como uma práxis projetiva, temos entorno da ideia do projeto a relação de design e fotografia.

Um outro aspecto que também se revela na fotografia é a dimensão do logro contra a natureza. Fontcuberta, inspirado por Flusser, nos diz: "toda a fotografia é uma ficção que se apresenta como verdadeira. Contra o que nos inculcaram, contra o que costumamos pensar, a fotografia mente sempre, mente por instinto, mente porque sua natureza não lhe permite fazer outra coisa" (2010, p. 13). Outro aspecto a ser observado na fotografia são suas ambigüidades, como a de ser objeto e imagem, nesse sentido a fotografia é projeto de design enquanto objeto, e simultaneamente aparelho produtor de imagens sintéticas, ou seja dispositivo de meta-design.

Flusser insistentemente no alerta para a revolução pela qual estamos passando, e aponto para o seu cerne que segundo ele é a mudança de atitude existencial do sujeito, que passa abandonar a noção de indivíduo para assumir a noção de projeto, que projeta um horizonte existencial em "rede dialógica de intersubjetividade universal e cujos fios correm informações e em cujos nós tais informações são armazenadas e processadas" (FLUSSER, S/D) onde não será mais possível distinguir o "dado" do "simulado".

Neste momento da história da humanidade, o termo design torna-se o conceito base de uma consciência operativa sobre a realidade externa e interna ao homem, e o termo fotografia, como uma imagem sintética, torna-se o sentido da percepção desta consciência e o instrumento de operação sobre uma realidade calculada. Nesta linha flusseriana de pensamento a fotografia é design e aparelho programador de meta-design. Design como produto consumo de produção industrial e meta-design como imagem que modelam o conhecimento, a vivência e o comportamento social.

Entendemos que com os argumentos aqui apresentados e previamente desenvolvidos, podemos fundamentar um entendimento teórico com uma perspectiva histórica, demonstrando a complexidade e densidade de uma discussão conceitual sobre design e fotografia e suas interrelações.

\section{Referências}

ADORNO, Theodor W. HORKHEIMER, Max. Dialética do Esclarecimento: fragmentos filosóficos. Rio de Janeiro: Jorge Zahar Ed., 1985.

BENJAMIN, Walter. Magia e Técnica, Arte e Política. São Paulo: Brasiliense, 1996.

BERMAN, Marshall. Tudo que é sólido desmancha no ar. São Paulo: Companhia das Letras, 1986.

CARDOSO, Rafael. Uma introdução à história do design. São Paulo: Edgar Blücher, 2004.

COHEN, Ted. Pictorial and photographic representation. Em: BARNOUW, E. et al. Intenational encyclopedia of communications, vol.3. Oxford: Oxford University Press, 1989.

COUTO, R.M.S. O Movimento Interdisciplinar de Designer Brasileiros em Busca de Educação Avançada. Tese de Doutorado. Rio de Janeiro: 1997.

COSTA, Helouise. A Fotografia Moderna no Brasil. São Paulo: Cosac Naify, 2004. 
DUBOIS, Philippe. L’acte photographique. Paris: Nathan \& Labor, 1983.

O Ato Fotográfico. Campinas, SP: Papirus, 2014.

FERRARA, Lucrecia D’Alessio. Olhar Periférico. São Paulo: USP, 1993. 277p. Cap.8: Desenho Industrial - Conceito, p. 193 - 194.

FORTY, Adrian. Objetos do desejo. São Paulo: Cosac Naify, 2007.

FLUSSER, Vilém. Pós-história: vinte instantâneos e um modo de usar. São Paulo: Annablume, 2011. . O Mundo Codificado. Organizador Rafael Cardoso. São Paulo: Cosac Naify, 2007. . O Universo das Imagens Técnicas. São Paulo: Annablume, 2008.

Paulo, S/D. . Do Sujeito em Projeto. Artigo não publicado disponível no arquivo Flusser, São

GOMES, L.V.N. Para uma Filosofia do Desenho ou Desenhismo. Recife: Editora Universitária UFPE, 1993.

KOSSOY, Boris, Fotografia e História. São Paulo: Ateliê Editorial, 2001.

LÖBACH, Bernd. Design industrial. São Paulo: Edgard Blücher, 2001.

MACHADO, Arlindo. O Quarto Iconoclasmo. Rio de Janeiro: Rios Ambiciosos, 2001. Ilusão Especular. São Paulo: Gustavo Gili, 2015.

NIEMEYER, Lucy. Design no Brasil: origens e instalação. Rio de Janeiro: 2AB, 1997.

SANTAELLA, Lucia e NÖTH, Winfried. Imagem. São Paulo: Editora lluminaurs, 1998.

SCHAEFFER, Jean-Marie. L'image précaire. Paris: Seuil, 1987.

SONESSON, Göran. Die Semiotik des Bildes: zum Forschungsstand am Anfag der 90er Jahre. Zeitschrift für Semiotik, n. 15, 1993.

Postphotography and beyond: from mechanical reproduction to digital production. Visio, vol.4, n.1, Printemps 1999, p.11-36.

SOUZA, Eudoro. Mitologia. Lisboa: Guimarães Editores, 1984.

VIRILIO, Paul. A arte do motor. São Paulo: Estação Liberdade, 1996.

WEBB, J. 0 design da fotografia. São Paulo: Editora GGBrasil, 2015. 